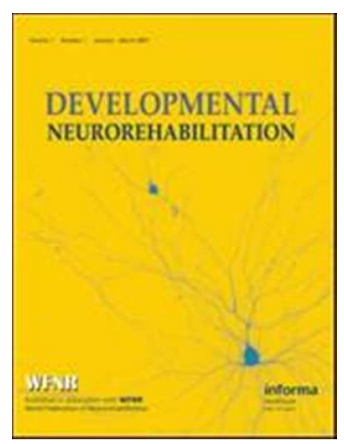

\title{
Beyond diagnosis: The relevance of social interactions for participation in inclusive preschool settings
}

\begin{tabular}{|r|l|}
\hline Journal: & Developmental Neurorehabilitation \\
\hline Manuscript ID & TPDR-2018-0061.R1 \\
\hline Manuscript Type: & Original Research \\
\hline Keywords: & participation, engagement, social interactions, independence, functioning \\
\hline \multicolumn{2}{|}{} \\
\hline
\end{tabular}

SCHOLARONE $^{\mathrm{m}}$
Manuscripts 


\begin{abstract}
This study aims to explore the role of three specific factors within the childenvironment interaction process - engagement, independence and social interactions - in influencing development and learning of children with disabilities in inclusive preschool settings. The main question is whether children can be categorised in homogenous groups based on engagement, independence and social interactions (proximal variables within a biopsychosocial framework of human development). The study also examined whether children with the same diagnosis would group together or separately, when trying to identify clusters of engagement, independence and social interactions, and additionally whether such clusters vary as a function of individual child characteristics, and/or as a function of structural and process characteristics of preschool environment. Data was taken from an intervention study conducted in mainstream preschools in Portugal. A person-centred cluster analysis was conducted to explore group membership of children with various diagnoses, based on their engagement, independence and social interaction profiles. Results show that children clustered based on similarity of engagement, independence and social interaction patterns, rather than on diagnosis. Besides, it was found that quality of peer interaction was the only predictor of cluster membership. These findings support the argument that participation profiles may be more informative for intervention purposes than diagnostic categories, and that preschool process quality, namely peer interaction, is crucial for children's participation.
\end{abstract}

Keywords: participation, engagement, social interactions, independence, functioning 


\section{Introduction}

It is recognised that the quality of children's interactions with the physical and social environment can influence learning, everyday functioning and development [1] [2]. This is the overarching principle proclaimed by biopsychosocial theories of human development [3]. However, little is known about the specific aspects within these interactions that play a role in promoting or hindering development and learning. Our main argument is that engagement, independence and social interactions may be understood as indicators of the overall level of participation of the child, and that participation provides a better picture of the child's everyday functioning than a single diagnosis.

The concepts of participation and engagement have both been studied as core outcomes of early childhood intervention e.g. [4] [5]. Children's participation in natural environments has been identified as a factor promoting development and providing a basic foundation for learning [5] [6]. Participation as a health-related concept [7] has been defined as "involvement in life situations" [8], p.18. Imms and Granlund [12] suggest that participation is a superordinate construct containing two dimensions, one dimension focusing on attending the activity (i.e., time spent in activity) and the second dimension focusing on being involved in the activity attended, i.e., engagement. Children's degree of participation has often been determined by measuring their engagement in stimulating everyday activities, which in turn has been linked to wellbeing, learning and development over time [9] [10] [11]. This link is particularly relevant for children with disabilities, who often experience participation restrictions [6]. Based on a synthesis of the literature in the field, the engagement dimension can be defined as a scenario where a child is attending an activity and is also: (a) interacting most of the time in contexts characterized by an interplay between the child and 
environmental factors, (b) focused on the activity in an active, persistent and attentive way, (c) revealing behaviors, which are context appropriate, (d) showing interest, motivation and/or fascination, (e) being open in relation to sensorial stimuli and/or cognitive stimuli, (f) possibly demonstrating satisfaction and (g) spending physical and/or mental energy, totally dedicated to the task while performing it [14] [15] [16] [17]. This definition considers not only the amount of time that the child is showing engagement in the activity, but also the quality (appropriateness) and level (from low to high) of engagement. Regarding the type of activities that children engage in, interaction with the environment may include social interactions with adults and with peers, but also non-social interactions (e.g., with objects, materials) [18]. The level of engagement refers to the level of involvement from not engaged to highly engaged/absorbed by the activity. Children can be engaged in activities requiring both low activity competence and high activity competence.

Activity competence can be operationalized as independence in performed skills, that is, skills and abilities the child can perform in every situation without support from others. To promote the child's independence, the environment must be engaging enough to trigger initiatives, and preschool teachers should provide continuous support, fostering interactions that expand the child's initiatives [13]. When children are independent in their preschool routines, they learn skills which allow them to interact with minimal assistance, and it also encourages them to explore and solve problems in the surrounding environment [20]. Engagement and independence are enhanced by social interactions.

Positive social experiences with both adults and peers are increasingly recognized as critical for children's developmental trajectories and overall wellbeing [21] [22] [23]. They are also regarded as the foundation of development and future academic 
achievement [24]. Social interactions may be considered as part of the surrounding context as perceived and co-constructed by the child and peers and adults [13]. The young child who successfully establishes social interactions, exhibits positive engagement with peers and is able to express him/herself appropriately, placing them in a good position to continue to thrive in a social world [25] [26].

As it stands, our argument is that grouping children based on engagement, independence and social interaction profiles may be useful for educators as indicators of participation, providing a functional alternative to the well-established medical approach to disability. Diagnostic categories based on medical or developmental measures often drive interventions without taking into account differences in individual functioning profiles. However, there is evidence that, for holistic intervention purposes, describing children's individual functioning profiles and the severity of the pattern of needs is more informative than a single diagnosis [27]. It has been observed, for example, that when trying to group children with various types of diagnosis based on the similarity of their functioning characteristics, the same diagnosis is present in various groups, thus indicating that the diagnostic category is not necessarily the best illustration of how a child functions [27]. However, preschool staff tend to be more knowledgeable of diagnosis than functioning [28], which has the potential to hinder a more individualised intervention [29].

This study aims to explore the role of three specific factors within the childenvironment interaction process - engagement, independence and social interactions - in influencing development and learning of children with disabilities in inclusive preschool settings. The main question is whether engagement, independence and social interactions (proximal variables within a biopsychosocial framework of human development) vary as a function of individual child characteristics, and/or as a function 
of structural and process characteristics of the preschool environment. Additionally, the issue of whether children with the same diagnosis group together or separately, when identifying clusters of engagement, independence and social interaction is examined.

\section{Method}

\section{Study design}

Data for this paper is retrieved from a broader project [Funding number] that conceptualizes children's participation in daily contexts as encompassing three pivotal components of functioning, namely engagement, social interactions and independence. The broader project followed a sequence of baseline assessment, intervention, and reassessment, designed to study factors associated with the functioning profiles of children with disabilities attending inclusive preschool settings.

In Portugal, where the study was conducted, legislation requires that all preschools are inclusive and children with disabilities receive adequate support from special education teams, in the least restrictive environment. Classrooms where children with identified disabilities are included might have specific adaptations regarding the total number of children attending (e.,g., maximum group size of 20 children when 2 children with disabilities are attending), the number of adults in the classroom and curriculum adaptions. Positive and responsive interactions are expected in all classrooms, and governmental guidelines for preschool education [30] state the need to ensure a high quality inclusive environment for all children. Children's participation and development must be considered by the teacher when planning and organising the learning environment; for example, all classroom routines must be planned purposefully and taking into account the teacher's ability to follow the children's own interests.

Structured activities and free play are both recommended, as well as time in small group 
and individual activities, with smooth transitions between them. Interventions with children with special education needs (SEN) must be contextualized and occur in the children's natural environments, meaning that the classroom environment is one of the main targets of intervention and the teacher role is fundamental [31] [32].

The present study uses data from the baseline assessment phase and data from the intervention phase of the broader project, in order to investigate the relationship between engagement, independence and social interaction and child and environmental characteristics. The participant researchers (in total 5 researchers with a degree in Psychology) combined the role of observers collecting data (during baseline assessment and intervention) and the role of a coach (during intervention). Visits to preschool were scheduled with teachers and data was collected within a whole day in order to gather information based on observation about the different preschool daily routines The baseline assessment focused on the quality of the preschool inclusive environment as well as on assessment of children's capacities. At the intervention phase the assessment was focused on children's functioning in the classroom. Intervention was developed focused on collaborative design and implementation of plans aiming to promote children's participation and functioning in daily routines. The research team was actively involved in the collaborative process of designing these plans, together with the classroom teachers, based on evidence from multi-agency assessments such us teachers's assessments, parents information and researchers observations. Functional goals were designed for each child, as well as specific strategies embedded in preschool routines [33]. The coaching role of reseachers aimed to facilitate joint reflection about the child's functioning profile in the context of daily routines, with the classroom teachers and support team. Based on the functioning profile information, 3 to 6 goals were developed and targeted across different routines for each child. For instance, for 
Maria, a 3 year old child with Down syndrome, a total of six dimensions were selected for intervention - e.g. directing attention, maintaining attention, initiating interactions, maintaining interactions, combining words into sentences, and manipulating. These were translated into functional goals embedded within the preschool classroom daily routines (e.g., Maria participates in a simple play script in the pretend play area - e.g., cooking and eating dinner - maintaining the activity and developing actions according to the play theme, for at least ten minutes); Maria participates in a pretend play activity by approaching her peers and responding to their requests - at least two). When defining the goals, the team jointly decided on the routines that seemed to be a better fit for addressing those goals. For instance, the team agreed that free play was the best routine to enhance Maria's competence in engaging in peer interactions. Nevertheless, these competences were also targeted in other moments, namely at transitions between routines and meal time. After each goal has been defined, intervention strategies were delineated so that all professionals working with the child (and the family, when the plan was extended to home routines) can understand what kinds of supports/strategies are most adequate. Once the plan was completed - with the goals and strategies defined and matched with the routines where the learning opportunities would naturally emerge for each child, intervention was carried out by the classroom teacher, and researchers monitored its implementation. [34]. Assessment focused on documenting children's engagement, independence and social relations across all classroom routines.

\section{Participants}

Participants were recruited from 35 inclusive preschool classrooms supporting children with identified disabilities from the greater metropolitan area of Porto, Portugal. This was a convenience sample as the preschools had previously participated in an early intervention community project conducted by the team of researchers. 
Twenty of the participant classrooms were state-funded $(57.14 \%), 4$ were private $(11.43 \%)$, and 11 were private non-profit organizations $(31.42 \%)$. Overall, the parents of 50 children consented to their participation in the study. Nevertheless, due to demands of the children's health conditions, 15 of them could not be observed and were excluded from the study. A total number of 35 caucasian children participated in the study, 18 boys and 17 girls. Children's mean age was 47.94 months $(S D=9.85)$, ranging from 20 to 64 months. All observed children had an identified disability and were receiving support from the special education/early intervention services.

Diagnostic categories included: language acquisition delay $(n=1)$; multiple disabilities $(n=2)$; Cerebral palsy $(n=4)$; Autism spectrum disorders $(n=3)$; Global development delay $(n=11)$; Genetic syndromes $(n=2)$; Sensory disability $(n=1)$; and other nonspecified category of diagnosis $(n=11)$.

Classrooms had 8 to 26 children enrolled $(M=20.75, S D=4.82)$. The number of children with disabilities attending the classrooms was, on average, $1.11(S D=0.32)$. Adult-child ratio ranged from 1:4 to 1:25 All lead teachers in the classrooms were female, and their mean age was 37.67 years $(S D=0.82)$. All teachers had at least one degree in preschool education and the number of years of formal education ranged between 14 and 17 years $(M=16.50 ; S D=0.82)$. The teachers' experience in preschool was very diverse $\left(M_{\text {years }}=14.06 ; S D=8.34\right)$, as well as their experience in working with children with disabilities $\left(M_{\text {years }}=4.63 ; S D=6.495\right)$. Three percent were in their first year of teaching and nine percent had no experience with children with disabilities. On the other hand, nine percent of the teachers had more than 20 years of experience in preschool teaching and six percent had more than 10 years of experience with children with disabilities.

\section{Ethics}


Informed consent was obtained from directors, parents and the teacher responsible for the classrooms. Ethical approval was obtained from the national data protection authority (Authorization number: 3539/2010).

\section{Measures}

The study used measures of child functioning, child capacities and classroom quality which are described below. At baseline assessment, measures of child capacity and preschool quality were used, namely the Assessment of Peer Relations (APR [35]), Abilities Index [36] and Quality of Inclusive Experience Measure (QIEM [37]). Following the intervention, child engagement, independence and social relations were documented with the Ecological Congruence Assessment (ECA [38]).

\section{Child functioning profile: Engagement; independence; social interactions}

\section{Ecological Congruence Assessment - adapted version (ECA; [38]). The ECA} intends to capture the ecology of early childhood inclusive settings. This is a childfocused measure. Data collection procedures include an observation during the preschool daily routines and provide a judgement-based rating for each routine. The following items are considered: (a) information about whether the target child is participating/doing the same activity as his/her peers (b) the child's needs for support in each activity - independence, (c) the child engagement in each routine (on a 5-point scale: $1=$ never engaged during the activity; 3 = engaged for about half the activity duration; $5=$ engaged for more than $85 \%$ of the activity duration) and (d) type of interactions: social (with peers and/or with adults); non-social (with objects; with self). ECA observational scores were calculated as follows: (a) engagement: average of all routines scores (b) independence: proportion of interactions in routines where the child needed support for the activity; (c) social interactions: proportion of interactions in routines/activities where the child was observed engaged with adults or peers. 
Authors state that this measure was developed to be used in inclusive classrooms where consulting specialists are available, being useful in setting goals relevant for child's participation. The observers were trained until they reached at least $80 \%$ interobserver agreement in the engagement dimension. Intraclass correlation was 0.98 . Concerning engagement a global score was computed by averaging the engagement scores of all routines observed. For the independence variable, a score was computed in order to obtain a proportion of occurrence of need of support (frequency of support need/total observation). For the social interactions variable, a proportion of occurrence was computed for interactions with peers and/or with adult.

\section{Child capacities}

Abilities Index [36]. The Abilities Index provides a global characterization of the child's abilities and disabilities in nine different areas: listening, behavior and social skills, intellectual function, limbs (use of hands, arms and legs), intentional communication, tonicity (muscle tonicity), physical integrity, vision and structural state. For each area the respondent scores the child's difficulties on a 6-point scale $(1=$ normal, $6=$ extreme dysfunction). A final score is obtained, describing the overall level of disability, accordingly with specific cut-off points for each value of the referred 6point scale [39], using the following criteria: $29 \leq \Sigma<58=$ Normal; $58 \leq \Sigma<87=$ suspect of dysfunction; $87 \leq \Sigma<116=$ small dysfunction; $116 \leq \Sigma<145$ = moderate dysfunction; $145 \leq \Sigma<174=$ severe dysfunction; and $\Sigma=174=$ extreme dysfunction [40] [41]. A lower score indicates higher functioning. Simeonsson, Chen and $\mathrm{Hu}$ [42] state that the instrument is useful to portray the differences between individuals as well as to document intra-individual variability of potential significance for matching needs to services. The development of the Abilities' Index drew on previous approaches to the profiling of child traits and functional characteristics described previously in other 
studies. The measure has been widely used with children with disabilities and studies provide evidence of its validity and reliability, including in Portugal [e.g., : 6; 40; 43; $44 ; 45 ; 46]$. In the present study, the measure presented a Cronbach Alpha of .89, showing good reliability.

Assessment of Peer Relations (APR; [35]). The APR was designed to assess every child (3-5 year olds) who demonstrates any difficulty establishing and maintaining successful interactions with their peers [35]. The items on the APR are based on the interactional development principles and its completion is made after a few days of observing the child interacting with peers in their contexts. It is organized in three sections, section I - foundational processes - which allows the gathering of the necessary data to design an intervention plan - consists of four components; section II, social strategies and social tasks - which captures how children solve problems associated with important social tasks ; and section III - processes - which intends for observers to speculate about the processes assessed in section I and II, by describing information about higher-order processes, social-cognitive processes and foundation processes of emotional regulation and shared understanding. Section III was not used in this study.

From section I - Foundation Processes - two components were used, the Involvement and the Emotional Regulation. Involvement refers to the child's level of complexity in engagement in activities and with peers (parallel play, onlooker, brief exchanges, prefers peers and complementary play, maintained play and complex social pretend play). The developmental complexity of engagement in preschool contexts has been found to be related to both child characteristics (i.e. developmental age and temperament) and to environmental characteristics [10] [19]. 
Emotional Regulation captures the child's ability to regulate emotions during peer interactions. It includes emotional factors important for peer interactions (e.g., how often the child "Becomes anxious when approached by others as indicated by gestures, facial expressions, or active withdrawal", "Becomes disorganized and upset during interactions with peers").

From the section II the Maintaining Play dimension was used. This refers to the child's ability to sustain group play with peers. It includes two common types of abilities, namely the child's ability to understand and adhere to a role and an activity structure, and the child's ability to manage tasks and adjust behaviours to the changing pattern of play and demands of play partners.

All items are rated on a 4 -point scale $(0=$ rarely; $4=$ almost always $)$. Given the characteristics of the participant children, an additional point was added to the rating scale - "Not Applicable". This measure has been mainly used in clinical settings [35], although it has also been used for research purposes and section I was translated and adapted for Portuguese children [e.g., 47; 48].

In the present study, composite variables were computed for each dimension of APR. Regarding the Involvement, the composite variable Social Engagement was computed by averaging its seven items $(\alpha=.80)$; For the Emotional Regulation the variable Adequate Emotional Regulation was computed by averaging two items (reciprocates; settles) $(\alpha=$.77). For Maintained Play - Adequate Strategies was computed by averaging its 4 items (re-engages; intensify request; reciprocates, deescalates) $(\alpha=.75)$. Role Strategies variable was by averaging 3 items (information, frame of reference, agreeable) $(\alpha=.94)$.

\section{Preschool Quality dimensions}


Quality of Inclusive Experience Measure (QIEM; [37]). The QIEM was used to measure the quality of the inclusive classroom environments in classrooms attended by children with disabilities, aiming to identify and measure the practices that are thought to promote more positive outcomes for young children with disabilities. This measure includes the assessment of Classroom Quality and Social Acceptance of Preschoolers With Disabilities, being organized in 7 independent dimensions of quality (Cronbach's alpha for dimensions used in the present study are presented in parentheses): (1) Program goals and purposes , (2) Staff supports and perceptions, (3) Accessibility and adequacy of the physical environment (4) Individualization $(\alpha=.94)$, (5) Children's participation and engagement, (6) Adult-child contacts and relationships ( $\alpha=.79$ ), and (7) Child-child contacts and interactions $(\alpha=.81)$. Interobserver agreement checks were conducted in $25 \%$ of classrooms. Average agreement in one observation was $99 \%$ for the Individualization dimension, $81.9 \%$ for the Adult-child contacts and relationships dimension, $99.5 \%$ for the Child-child contacts and interactions dimension. All subscales were rated on a 5-point scale for most items. The measure was previously used in Portuguese contexts, showing good reliability [29].

The present study focuses on three of the QIEM's dimensions assessed at child level:

(1) The individualization, which provides information on the extent to which individualized goals and interventions are planned and implemented; (2) Adult-child contacts and relationships (referred from this point as Quality of Teacher interactions), which captures the adults' involvement with children, as well as the quality of their interactions in terms of tone, responsiveness and support; (3) Child-child contacts (referred from this point as Quality of Peer Interactions), which encompasses: the nature of interactions in terms of their affect, the frequency of interactions, the initiator of interactions, the reciprocity of interactions - whether the child with disabilities 
responded to the initiations by his/her classmates, to children with and without disabilities.

\section{Data Analysis}

\section{Cluster analysis}

Cluster analysis was conducted to ascertain whether children can be clustered into homogeneous groups [49] according to ratings of engagement, independence and social interactions as measured by the ECA. This analytic approach is similar to discriminant analysis and is used when the intention is to classify an initial data set in groups or categories using the observed values of the variables, when neither the number of group members nor their membership is known [49]. Given the assumption that children differ based on their profiles of engagement, independence and social interactions in daily routines, clusters analysis was considered the most appropriate method for exploring the nature of their functioning profiles. When there are no pre-defined expectations regarding the number of clusters to be found, a hierarchical cluster analysis is useful [50]. Hierarchical cluster analysis uses an algorithm to produce a dendrogram that assembles variables into a single tree, to evaluate intra- and inter-group similarities and differences. This approach is similar to principal component analysis, though preassumptions regarding the variables structure is not required [51].

In the present study, the hierarchical agglomerative method was selected to explore the "natural" number of clusters [52]. Through this method, clusters are formed based on the nearest pairs of cases, in various iterations, according to a selected distance measure, until all data is gathered in one cluster [49]. The measure used was the squared Euclidian distance. As ECA variables were on different scales, they were first standardized, based on the overall group scores $(M=0, S D=1.00)$ before the squares of the Euclidian distances were calculated between each pair of children. To identify 
homogeneous sub-groups of children and to determine the initial clustering solution, Wards agglomerative procedure was conducted. Additionally, three other hierarchical agglomerative procedures were conducted to test internal validity: (a) between-groups linkage; (b) within-groups linkage; and (c) furthest neighbour. This procedure aimed to compare the agglomeration process results, as well as to evaluate this initial solution and internally validate the structure of the established categories.

\section{Inferential analysis}

To examine whether the resulting clusters of children differed on other variables at child level, external validity was examined by testing the clusters for mean differences on Abilities Index and Peer Relations. Mann-Whitney non-parametric statistic was used, based on the size of the two groups, obtained after the clustering process [49]. Cohen's $r$ [49] was used to determine the magnitude of differences between groups.

\section{Logistic Regression}

Binary Logistic regression was used to test models to explore the ability of two sets of variables - child characteristics and preschool classroom quality characteristics - to predict cluster membership. The parameters were estimated using maximum-likelihood estimation, which selects coefficients that make the observed values most likely to have occurred. The ambition was to fit a model to the data that allowed for estimation of values of the outcome variable from known values of the predictor variables. Forced entry method was used, as this is the most appropriate method for theory testing. All covariates were entered in one block and the parameter estimates were calculated for each block [54] [55].

\section{Results}

Children grouping based on engagement, independence and social interactions 
Two, three and four-cluster solutions were explored as potential results of the cluster analysis procedure. A two-cluster solution was found as the most interpretable. All four clustering methods resulted in the same two-cluster solution, indicating that children's data could be categorised in two cluster groups. Cluster 1 was named Higher Level Functioning and Cluster 2 was named Lower Level Functioning. Descriptive results for the three dimensions (Engagement, Independence and Social interactions) in the two clusters are presented in Table 1. Cluster 1 named Higher Level Functioning includes 18 children that are characterized by higher levels of Engagement, Independence and Social Interactions, consistently in their daily routines. Cluster 2 named Lower Level Functioning includes 17 children which obtained lower levels of Engagement, Independence, and Social Interactions, indicating that children in this group had lower levels of functioning in preschool daily routines.

The clusters 'external validity was addressed by comparing the two groups of children on the Abilities Index dimensions and on the four dimensions of the social skills as measured by the APR (Table 2). Results from the Mann-Whitney nonparametric test conducted showed that children in Cluster 1 presented higher scores on the following Abilities Index domains: Social Skills, Appropriateness of Behaviour, Intellectual Function, Understanding others and Communicating with others. The Global Abilities Score was lower indicating that children in cluster 1 had higher developmental level $(M=52.84 ; D P=18.91)$. Moreover, moderate to large differences between children in the two clusters were found in all APR dimensions, with a large effect size $(r>.50)$.

Finaly, diagnostic categories in each cluster were analysed. Table 3 shows the diagnosis distribution by cluster. The number of children in this study does not allow to 
statistically compare differences between the groups of children. However children with different diagnosis are found in both clusters.

Insert Table 1

Insert Table 2

Insert Table 3

\section{The predictive power of child and context variables on cluster membership}

Binary Logistic regression (see Table 4) was used to determine which factors - child characteristics and/or preschool classrooms quality characteristics - can predict children's cluster membership. By inspecting results when only the constant was included - baseline model -, the overall percentage of correctly classified cases is $51.4 \%$, meaning that 18 children displayed higher functioning pattern and 17 displayed lower functioning pattern. The predictive variables were then added to the model, namely child variables (age, Abilities profile) and classroom quality characteristics (quality of individualization practices, quality of teacher-child and quality of peer interactions) to define cluster membership for each child. The set of predictors was tested, and the Omnibus test of Model Coefficients gave an overall indication of how well the model performed over and above the results obtained for the baseline model. This coefficient was significant $(p<.0001)$ indicating that the model with the predictors has a better fit then the baseline model. The Hosmer and Lemeshow's test value of 7.80 $(p>.05)$ also supports our model. When the set of predictors was entered, the model was able to improve the accuracy of its prediction by correctly classifying $85.7 \%$ of cases. Among the variables in the model, only the Quality of Peer Interactions significantly contributed to its predictive ability, indicated by the significance of the Wald statistics $(p<.05)$. The model's global predictive power was good ( $85.7 \%)$. Hosmer and Lemeshow's goodness-of-fit test, Cox and Snell $\mathrm{R}^{2}$ and Nagerlkerke's $\mathrm{R}^{2}$ 
were good (.54 and .72, respectively). Results indicate that Higher Quality of Peer Interaction tends to predict membership in the higher participation group of children (Cluster 1).

\section{Insert Table 4}

\section{Discussion}

This study investigates whether children with disabilities in preschool can be grouped based on three specific factors within the child-environment participation process, namely engagement, independence and social interaction, regardless of their diagnosis. Additionally, adopting a person-centred approach, the aim was to investigate child characteristics and/or contextual characteristics that predict child's membership to a specific group based on functioning profiles. Results show that participation provides a better picture of the child's everyday functioning than their diagnosis, and that engagement, independence and social interactions may be understood as indicators of child overall participation. Taking these three dimensions together as a participation outcome compound, it seems that both child and contextual factors affect participation processes in inclusive settings.

This study showed that children could be clustered based on: (a) engagement in activities (b) activity competence measured as independence/performance in daily routines; and (c) social interactions. Moreover, cluster groups differed significantly regarding child capacities (e.g., the ability to communicate and understand, and social skills) and on teachers' perceptions of the child's social skills, regardless of their diagnosis. The identification of a low and a high functioning cluster based on aspects of the child-environment interaction process reveals the utility of a functioning approach instead of a diagnostic approach for assessment and subsequent planning of interventions. In fact, the cluster analyses did not overlap with diagnostic categories. 
This may indicate that groups formed based on functioning may change depending on the adequacy of the proximal environments provided to children over time, eve though the diagnosis remains the same.

If participation encompasses the interaction of the child with the physical and social environment, as well as the motivation to participate in activities, this has consequences for support and services. In order to design appropriate support services for children with identified disabilities in inclusive educational contexts, the quality of the children's interactions with the physical and social environment must be considered, in line with biopsychosocial theories of human development. A number of factors at different ecological levels - from the political, organisational, social and cultural to classroom interactions - must be considered rather than the child's diagnosis only.

In Portugal, as in some other countries, Individualized Education Plans are mandated by law, following international conventions that recommend focusing assessment and intervention procedures on participation outcomes. This way of reasoning requires a shift in assessment-intervention paradigms from a focus on deficits in the child's development to a focus on child functioning and participation in natural settings, which changes over time. Difficulties in this paradigm shift were highlighted in a study analysing Individualized Education Programs in pre-schoolers with disabilities, attending inclusive special education [56]. The study results show a lack of consistency between assessment and intervention, with few domains being included in both assessment and intervention [56]. This result, as well as the evidence in favour of a functioning approach shown in the present study, point to the need for future research to focus on developing instruments to observe individual child engagement, to determine their social interactions and degree of independence in daily activities. Such instruments can be used to monitor the efficacy of procedures aimed at increasing participation and 
their implementation. If this is implemented, early childhood intervention professionals will be in a better position to plan opportunities aiming to improve children's participation. Training teachers on how to use such measures in their education planning and daily interactions will support them in adequately monitoring their intervention plan in order to meet each child's unique needs.

The perception that early childhood intervention professionals' have on participation outcomes is also important to consider when facilitating this aforementioned paradigm shift. A study by Eriksson and Granlund [7] underline the relevance of investigating the concept of participation amongst people within the child's close environment. Preschool teachers' conceptions may affect attitudes and actions in providing opportunities, as well as the form and content of the service provided. However, more research is needed on how to influence professionals' understanding of participation and on how to adjust and plan their actions to address each individual functioning profile.

The results of the cluster analysis conducted in this study show that children group in a high-level functioning cluster and a low level functioning cluster and that none of the child characteristics alone predicted cluster membership. In fact, although there are differences between clusters in terms of children's overall capacities, such capacities are not predictive of cluster membership for each individual child - it seems to be the environment that explains functioning differences. Indeed, only the quality of peer interactions predicted cluster membership, ths suggesting this is the variable professionals should target in inclusive prechool education. However, probably several other factors work together to produce a positive participation outcome, and the way factors combine may also vary between individuals [57]. It would be expected that better teacher involvement, tone, responsivity and support for the lower functioning group would be associated with an improvement in social interactions with adults and 
peers. Previous literature emphasised that the quality of the teacher-child relationship is a key component of Early Childhood Education and Care (ECEC) quality, as young children learn about the world mainly through transactions with adults and through play with activities and materials provided by adults [58] [59] [60] [61]). Adults are expected to play a prominent role in child developmental processes, particularly in children with developmental disabilities who need additional support to adequately participate in their environments [3] [62]. However, teacher's individualisation practices and the quality of teacher-child interactions were not significant predictors of children's cluster membership. One possible explanation to this might be a tendency for teachers to use the same interactional style with all children, regardless of their functioning profile. In addition, children spend much time in preschool activities intended to elicit child initiated "free play". In such activities peer intercaction may have a stronger direct influence than adult-child interaction.

For appropriate inclusive practices to occur, above equality in interactions, children have the right to equity of opportunities in their daily environments. This result is in line with findings from previous studies which show that some preschool settings provide medium quality for typically developing children but inappropriate quality services for children with disabilities [43] [63] [64] [65] [66] [67] [68]. In another study conducted in Portugal, teachers were found to provide poor responsiveness and lack of warmth in their interactions [38] and ECEC services that children received were characterized by a low degree of individualisation [29] [63]. In the current study, we can hypothesise that if more support was in place to target children's engagement in activities, the gap between social interaction, engagement and independence between the two groups could have been smaller, thus promoting a more inclusive environment. Future research should focus on documenting specific teacher-child interaction processes and its relation 
with participation outcomes. This is even more relevant when we know that in some inclusive preschool settings children tend to spend nearly fifty percent of their time in whole group activities structured and monitored by the teacher [69].

Inversely to children's capacities and to teacher-child interactions, the quality of peer interactions predicted cluster membership showing that higher quality child-child interactions were associated with membership to the high functioning group and lower quality child-child interactions were associated with membership to the low functioning group. This variable, found to be pivotal in the model, helps to conceptualise the process of participation in a practical way, as it encompasses not only the frequency of child-child contacts, but also specific quality aspects of peer interactions as they occur in ongoing activities - e.g., the length of interactions and the emotional tone between children with and without disabilities in the classroom. This finding is in line with previous research showing that the quality of peer interactions predicted children's participation in inclusive settings. Consequently, quality peer interaction can be seen as a core dimension of inclusion [29] [70] [71].

Some limitations to this study need to be acknowledged and results must be interpreted carefully. First, the sample size and variety of diagnosis was limited, not allowing further analyses about the role of diagnoses in the identified participation profiles. Secondly, the fact that teacher interaction quality did not predict group membership may be due to a measurement caveat. Unlike the procedure used to measure child-child interaction quality, that was based on direct observation and coding of frequency and length of the interactions, the assessment of the quality of teacherchild interaction in terms of tone, responsiveness and support was coded through a judgment-only procedure. Lastly, blind observers were not considered in the data collection and coding process. 
1

2

3

4

5

6

7

8

9

10

11

12

13

14

15

16

17

18

19

20

21

22

23

24

25

26

27

28

29

30

31

32

33

34

35

36

37

38

39

40

41

42

43

44

45

46

47

48

49

50

51

52

53

54

55

56

57

Despite these limitations, our findings contribute to a better understanding of the concept of participation in inclusive envronments and highlight the relevance of planning educational interventions that are purposeful, with implications for teacher training and continuous professional development. The importance of assessing functioning profiles, as opposed to diagnostic labels, as the starting point for planning educational interventions is highlighted, along with the role of peer interactions as the main generator of learning and development. 


\section{References}

[1] Bronfenbrenner U. Making human beings human. Bioecological perspectives on human development. London: Sage Publications; 2005.

[2] Sameroff A J. A unified theory of development: A dialectic integration of nature and nurture. Child Development 2010; 81(1): 6-22.

[3] Bronfenbrenner U, Morris, P A. The bioecological model of human development. In: Damon W, Lerner R M, editors. Handbook of Child Psychology, (6th ed., vol. 1). New Jersey, Hoboken, NJ: Wiley; 2007. pp. 793-828.

[4] Adolfsson M, Granlund M, Pless M. Professionals' views of children's everyday life situations and the relation to participation. Disability \& Rehabilitation 2012; 34(7): $581-592$.

[5] Almqvist L. Patterns of engagement in young children with and without developmental delay. Journal of Policy and Practice in Intellectual Disabilities 2006; 3(1):65-75.

[6] Simeonsson R J, Carlson D, Huntington G, McMillen J, Brent J. Students with disabilities: A national survey of participation in school activities. Disability and Rehabilitation 2001; 23(2): 49-63.

[7] Eriksson L, Granlund M. Conceptions of Participation in Students with Disabilities and Persons in Their Close Environment. Journal of Developmental \& Physical Disabilities 2004; 16(3): 229-245.

[8] World Health Organization. International classification of functioning, disability and health (ICF). Geneva, Switzerland: WHO; 2001.

[9] Aydogan C. Influences of instructional and emotional classroom environments and learning engagement on low-income children's achievement in the prekindergarten year. [dissertation] Vanderbilt University; 2012. Unpublished manuscript.

[10] de Kruif R E L, McWilliam R A. Multivariate relationships among development age, global engagement and observed child engagement. Early Childhood Research Quarterly 1999;14: 515-536.

[11] Pinto AI, Barros S, Aguiar C, Pessanha M, Bairrão J. Relações entre idade desenvolvimental, dimensões do comportamento adaptativo e envolvimento observado [Relationships between developmental age, dimensions of adaptive behavior and observed engagement]. Análise Psicológica 2006; 24(4): 447-466. 
[12] Imms C, Granlund M. Participation: Are we there yet. Australian Occupational Therapy Journal 2014; 291-292.

[13] Imms C, Granlund M, Wilson P, Steenbergen B. Participation, both a means and an end: a conceptual analysis of processes and outcomes in childhood disability. Developmental Medicine \& Child Neurology 2017; 1-10. doi: 10.1111/dmcn.13237 [14] Almqvist L, Uys C J E, Sandberg A. The concepts of participation, engagement and flow: A matter of creating optimal play experiences. South African Journal of Occupational Therapy 2007; 37(3): 8-13.

[15] Laevers F. Assessing the quality of childcare provision: "Involvement" as criterion. Researching Early Childhood 1997; 3:151-165.

[16] McWilliam R A, Bailey D B. Promoting engagement and mastery. In: Bailey D B, Wolery M, editors. Teaching infants and preschoolers with disabilities, 2nd editon. New York: MacMillan Publishing Company; 1992. pp. 230-255.

[17] Ulich M, Mayr T. Children's involvement profiles in daycare centres. European Early Childhood Education Research Journal 2002; 10(2): 127-143.

[18] Raspa M J, McWilliam R A, Ridley SM. Child care quality and children's engagement. Early Education and Development 2001; 12: 209-224.

[19] McWilliam R A, Bailey D B. Effects of classroom social structure and disability on engagement. Topics in Early Childhood Special Education 1995; 15:123-147.

[20] McWilliam R A, Casey A M. Engagement of every child in the preschool classroom. Baltimore, MD: Paul H. Brookes Publishing Company; 2008.

[21] American Academy of Pediatrics [Internet]. The social emotional development of young children: A resource for Healthy Start staff. Available from National Healthy Start Association (NHSA) http://www.nationalhealthystart.org/site/assets/docs/NHSA_SocialEmotional_1.pdf. [22] Cooper J L, Masi R, Vick J. Social-emotional development in early childhood: What every policymaker should know. Available from http://www.nccp.org/publications/pub_882.html [23] Thompson R A, Lagattuta K H. Feeling and understanding: Early emotional development. In: McCartney K, Phillips D, editors. Blackwell handbook of early childhood development. Malden, MA: Blackwell. 2006. p. 317-337.

[24] National Research Council and Institute of Medicine From neurons to neighborhoods: The science of early childhood development. In: Shonkoff J P, Phillips D A. editors. Washington, DC: Committee on Integrating the Science of Early 
Childhood Development, Board on Children, Youth, and Families, Commission on Behavioral and Social Sciences. National Academy Press. 2000.

[25] Denham S A. Social-emotional competence as support for school readiness: What is it and how do we assess it? Early Education \& Development 2006; 17(1): 57-89. [26] McWilliam R A. Foundations for learning in a modern society. Nashville, Tennessee: Center for Child Development, Vanderbilt University Medical Center. Unpublished Manuscript. 2005.

[27] Castro S, Pinto A I. Matrix for assessment of activities and participation:

Measuring functioning beyond diagnosis in young children with

disabilities. Developmental Neurorehabilitation 2015; 18(3).

doi: $10.3109 / 17518423.2013 .806963$

[28] Tzivinikou S, Papoutsaki K. Studying teaching methods, strategies and best practices for young children with special educational needs. Early Child Development and Care 2016; 186 (6): 971-980. doi: 10.1080/03004430.2015.1071101

[29] Aguiar C, Moiteiro A R, Pimentel J. Classroom quality and social acceptance of preschoolers with disabilities. Infants \& Young Children 2010; 23 (1):34-41. doi:

10.1097/IYC.0b013e3181c9766e

[30] Silva I L, Marques L, Mata L, Rosa M. Orientações Curriculares para a Educação Pré-Escolar [Curriculum Guidelines for Preschool Education]. Ministry of Education and General Direction of Education. Portugal. 2016.

[31] Gamelas, A. M. Contributos para o Estudo da Ecologia de Contextos Pré-Escolares Inclusivos [Contributions to the study of inclusive preschool contexts ecology]. Lisbon: Ministry of Education. 2003.

[31] Pinto, A. I., Grande, C., Aguiar, C., de Almeida, I. C., Felgueiras, I., Pimentel, J. S., ... Lopes-dos-Santos, P. Early Childhood Intervention in Portugal: An Overview Based on the Developmental Systems Model. Infants And Young Children 2012; 25:4. [33] McLaughlin T, Snyder P, Hemmeter M L. Using Embedded Instruction to Support Young Children's. Learning Exchange Magazine 2011; 49-52.

[34]. Authors

[35] Guralnick M J. Assessment of Peer Relations. Child Development and Mental Retardation Center. University of Washington. 2003.

[36] Simeonsson R J, Bailey D B. ABILITIES Index. Chapel Hill, NC: Frank Porter Graham Development Center, University of North Carolina. 1991. 
[37] Wolery M, Paucca T, Brashers M S, \& Grant, S. Quality of Inclusive Experiences Measure. Chapel Hill: University of North Carolina, FPG Child Development Center. 2000.

[38] Wolery M, Brashers M S, Grant S, Pauca T. Ecological congruence assessment for classroom activities and routines in childcare. Chapel Hill, NC: Frank Porter Graham Child Development Center. 2000.

[39] Simeonsson R J, Bailey D B, Smith T, Buysse V. Young children with disabilities: functional assessment by teachers. Journal Developmental and Physical Disabilities 1995; 7: 267-284. doi:10.1007/BF02578431

[40] Simeonsson R J. Developmental weights for the ABILITIES Index. Chapel Hill, NC: Frank Porter Graham Development Center, University of North Carolina. [unpublished manuscript]. 1995.

[41] Daley T C, Simeonsson R J, Carlson E. Constructing a measure of severity of disability in a national sample of preschoolers with disabilities. University of North Carolina at Chapel Hill, NC: Frank Porter Graham Development Center. [unpublished manuscript]. 2006.

[42] Simeonsson R J,Chen J, Hu Y. Functional assessment of Chinese children with The ABILITIES index. Disability \& Rehabilitation 1995; 17(7):400-10. doi:10.3109/09638289509166728

[43] Grande C. Estudo do impacto das interacções educadora-criança no envolvimento das crianças com necessidades educativas especiais em contexto de creche e de jardimde-infância. [Study of the impact of teacher-child interactions in the engagement of children with special educational needs in the context of day care and preschool]. ISBN: 978-972-31-1479-9 Lisbon: Calouste Gulbenkian Foundation. 2013.

[44] Grande C, Aguiar C. O Índice de Capacidades: dois estudos [The abilities Index: two studies]. In A. S. Ferreira, A. Verhaeghe, D. R. Silva, L. S. Almeida, R. Lima, \& S. Fraga, Actas do VIII Congresso Iberoamericano de Avaliação/Evaluación Psicológica XV Conferência Internacional Avaliação Psicológica: Formas e Contextos. Braga: Psiquilíbrios Edições. 2011. 1146-1160 p. [45] Simeonsson R J, Scarborough A A, Hebbeler K M. ICF and ICD codes provide a standard language of disability in young children. Journal of Clinical Epidemiology 2006; 59(4): 365-373.

[46] Castro S. The assessment-intervention process of young children with autism: contributions of the international classification of functioning, disability and health for 
children and youth. [dissertation/PhD thesis]. Porto, Portugal: Faculty of Psychology and Educational Sciences of Porto University; 2006.

[47] Soares E, Serrano A, Guralnick M. Translation, adaptation and content validation of section I of the scale "Assessment of Peer Relations" into the Portuguese language. Journal of Human Growth and Development 2013; 23(1): 31-40.

[48] Ferreira, D. Temperamento e participação social com pares em crianças com perturbação do espectro do autismo (PEA) [Temperament and social participation with peers in children with Austim Spectrum Disorder (ASD)]. [Unpublished Master Dissertation]. Porto, Portugal: Faculty of Psychology and Educational Sciences of Porto University; 2011.

[49] Everitt B S, Landau S, Leese M, Stahl D. Index. In: John Wiley \& Sons, Ltd. Cluster Analysis. 5th edition. Chichester, UK; 2011. doi:

10.1002/9780470977811.index

[50]Bergman L R, Magnusson D, El Khouri B M. Studying individual Development in An interindividual Context: A Person-oriented Approach (Paths Through Life). London: Lawrence Earlbaum Associates, Publishers. 2003.

[51] Marôco J. Análise Estatística com o SPSS Statistics.: $7^{\mathrm{a}}$ edição. ReportNumber, Lda. 2018.

[52] Afifi A A, Clark V. Computer-aided multivariate analysis. 3rd edition. Florida: Chapman \& Hall/CRC; 1999.

[53] Cohen J. Quantitative Methods in Psychology: A power Primer. Psychological Bulletin 1992; 112: 155-159.

[54] Field A. Discovering statistics using SPSS. 2nd edition. London: Sage; 2005.

[55] Hilbe J M. Practical Guide to Logistic Regression. Taylor and Francis. Florida: Boca Raton; 2015.

[56] Castro S, Pinto A I, Simeonsson R J. Content analysis of Portuguese Individualized Education Programs for young children with Autism using the ICF-CY framework. European Early Childhood Education Research Journal 2012.

http://dx.doi.org/10.1080/1350293X.2012.704303

[57] Rusk R, Vella-Brodrick D, Waters L. A complex dynamic systems approach to lasting positive change. The synergistic change model. The Journal of positive psychology 2017; 13(4): 406-418.doi.org/10.1080/17439760.2017.1291852

[58] Howes C, Burchinal M, Pianta R, Bryant D, Early D, Clifford R, Barbarin O. Ready to learn? Children's pre-academic achievement in pre-kindergarten programs. 
Early Childhood Research Quarterly 2008; 23(1): 27-50.

doi:10.1016/j.ecresq.2008.08.00

[59] Mashburn A, Pianta R. Opportunity in early education: Improving teacher-child interactions and child outcomes. In: Reynolds A, Rolnick A, Englund M, Temple J. editors. Childhood Programs and Practices in the First Decade of Life: A Human Capital Integration. New York, NY: Cambridge University Press; 2010. p. 243 - 265. [60] Rudasill K M, Rimm-Kaufman S E. Teacher-child relationship quality: The roles of child temperament and teacher-child interactions. Early Childhood Research Quarterly 2009; 24(2): 107-120. doi:10.1016/j.ecresq.2008.12.003 [61] Sabol T J, Pianta R. Recent trends in research on teacher-child relationships. Attachment and Human Development 2012; 14(3): 213-231.

[62] Sameroff A J. edition. The Transactional Model of Development: How Children and Contexts Shape Each Other. Washington, DC: American Psychological Association. 2009.

[63] Gamelas A M. Contributos para o estudo da ecologia de contextos pré-escolares inclusivos. [Contribute for the study of the ecology of preschool inclusive contexts]. Lisboa: Departamento da Educação Básica. 2003.

[64] Lillvist A. Observations of social competence of children in need of special support based on traditional disability categories versus a functional approach. Early Child Development \& Care 2010, 180(9):1129-1142. doi:10.1080/03004430902830297 [65] Lillvist A. The applicability of a functional approach to social competence in preschool children in need of special support. studies in psychology. Akademisk avhandling [dissertation]. Örebro University. 2010.

[66] Lillvist A, Granlund M. Preschool children in need of special support: prevalence of traditional disability categories and functional difficulties. Acta Paediatrica. 2010; 99(1): 131-134. doi:10.1111/j.1651-2227.2009.01494.x

[67] Lillvist A, Sandberg A, Björck-Åkesson E, Granlund M. The construct of social competence. How preschool teachers define social competence in young children. International Journal of Early childhood 2009; 40 (1):51-68.

[68] Pinto A I, Pessanha M, Aguiar C. Effects of home and childcare quality on children's language and communication development at 26 and 68 months. Early Childhood Research Quarterly 2013; 28: 94-101. doi:10.1016/j.ecresq.2012.07.001 
[69] Coelho V, Pinto A I. Child engagement and interactive processes in inclusive preschool settings. International Society on Early Intervention Conference; 2016 June. 8-10; Stockholm, Sweden.

[70] Ferreira T, Coelho V, Pinto A I. Early Childhood Intervention Practices Based on Evidence: The Case of Participation. European Conference on Developmental Psychology ECDP; 2012; Bolonha, Itália: 2012. 485-490 p.

[71] Sjöman M, Granlund M, Axelsson A K, Almqvist L, Danielsson H (submitted). Social Interactions - Predictor of Children's Engagement and Hyperactivity in Preschool. Early Education and Development. 
Table 1. Descriptive Results in the Dimensions of Children's Participation (Engagement, Independence and Social Interactions) for the Two

\section{Clusters.}

\begin{tabular}{lllllllllll}
\hline \multicolumn{10}{c}{ Clusters } \\
\hline & Cluster 1 $(n=18)$ & \multicolumn{1}{c}{ Cluster 2 $(n=17)$} & & & \\
Engagement & $\boldsymbol{M}$ & $\boldsymbol{S D}$ & $\boldsymbol{M d n}$ & $\boldsymbol{M}$ & $\boldsymbol{S D}$ & $\boldsymbol{M d n}$ & $\boldsymbol{U}$ & $\boldsymbol{z}$ & $\boldsymbol{r}^{*}$ \\
Independence & .10 & .52 & 4.01 & 2.58 & .48 & 2.57 & $4.00^{* *}$ & -4.9 & -.83 \\
Social & .31 & .89 & .09 & .13 & .00 & $1.5^{* *}$ & -5.1 & -.86 \\
interactions & 1.4 & .29 & 1.39 & 1.1 & .32 & 1.0 & $75.00^{*}$ & -2.6 & -.44 \\
\hline
\end{tabular}

$* r=Z / \sqrt{ } \mathrm{N}$ (Rosenthal, 1991; Field, 2005). Effect size (small if $r=.10$, moderate if $r=.30$ and large if $r=.50$ ). ${ }^{*} \mathrm{p}<.05 ; * * \mathrm{p}<.01 ; * * * \mathrm{p}<.001$ 
Table 2. Differences Found Between Clusters Considering the Abilities' Index and APR Dimensions.

\begin{tabular}{|c|c|c|c|c|c|c|c|c|c|}
\hline & \multicolumn{6}{|c|}{ Clusters } & \multirow{2}{*}{\multicolumn{3}{|c|}{ Mean differences }} \\
\hline & \multicolumn{3}{|c|}{ Cluster $1(n=18)$} & \multicolumn{3}{|c|}{ Cluster $2(n=17)$} & & & \\
\hline & $M$ & $S D$ & $M d n$ & $M$ & $S D$ & $M d n$ & $\boldsymbol{U}$ & $z$ & $r^{*}$ \\
\hline Social Skills & 2.10 & 1.20 & 1.40 & 5.68 & 2.00 & 7.00 & $276.0^{* *}$ & 4.23 & .72 \\
\hline $\begin{array}{l}\text { Inappropriate } \\
\text { Behaviour }\end{array}$ & 2.74 & 1.95 & 1.70 & 5.70 & 3.00 & 6.80 & $235.5^{*}$ & 2.95 & .50 \\
\hline $\begin{array}{l}\text { Intellectual } \\
\text { Function }\end{array}$ & 4.0 & 2.91 & 2.00 & 8.35 & 3.10 & 10.00 & $263.0^{* *}$ & 3.72 & .63 \\
\hline $\begin{array}{l}\text { Understanding the } \\
\text { others }\end{array}$ & 2.10 & 1.50 & 1.20 & 4.10 & 1.75 & 4.80 & $244.5^{*}$ & 3.20 & .54 \\
\hline $\begin{array}{l}\text { Communicating } \\
\text { with others }\end{array}$ & 2.50 & 1.25 & 2.50 & 4.41 & 1.18 & 5.00 & $265.0^{* *}$ & 3.79 & .64 \\
\hline $\begin{array}{l}\text { Integrity of } \\
\text { Physical Health }\end{array}$ & 2.75 & 2.00 & 1.50 & 4.32 & 2.24 & 6.00 & 209.5 & 2.04 & .34 \\
\hline $\begin{array}{l}\text { Abilities Index: } \\
\text { Global Score }\end{array}$ & 52.84 & 18.91 & 51.40 & 73.61 & 26.63 & 65.60 & $228.0^{*}$ & 2.48 & .42 \\
\hline Involvement & 2.43 & .69 & 2.21 & 1.43 & .56 & 1.43 & $26.0 * *$ & -3.95 & -.67 \\
\hline $\begin{array}{l}\text { Adequate } \\
\text { Emotional } \\
\text { Regulation } \\
\text { Maintained Play }\end{array}$ & 2.78 & .59 & 2.67 & 2.01 & .61 & 1.80 & $39.0 * *$ & -3.51 & -.59 \\
\hline $\begin{array}{l}\text { - adequate } \\
\text { strategies }\end{array}$ & 1.94 & .48 & 2.00 & .93 & .74 & 1.00 & $34.5^{* *}$ & -3.66 & -.62 \\
\hline Role Strategies & 2.28 & 1.01 & 2.33 & .78 & .80 & 1.00 & $37.5^{* *}$ & -3.59 & -.61 \\
\hline
\end{tabular}


Table 3. Number of Children in Each Cluster According to Diagnosis.

\begin{tabular}{lcc}
\cline { 2 - 3 } & \multicolumn{2}{c}{ Groups } \\
\hline Diagnosis & Cluster $1(n=18)$ & Cluster $2(n=17)$ \\
\hline Language acquisition delay & 0 & 1 \\
Multiple disabilities & 0 & 2 \\
Cerebral palsy & 3 & 1 \\
Autism spectrum disorders & 0 & 3 \\
Global development delay & 6 & 5 \\
Genetic syndromes & 1 & 1 \\
Sensory disability & 1 & 0 \\
Other & 7 & 4 \\
\hline
\end{tabular}


Table 4. Binary Logistic Regression Results for Cluster Membership.

\begin{tabular}{|c|c|c|c|c|c|c|c|c|}
\hline Variable & B & SE & Wald & $\mathrm{df}$ & $p$ & $\operatorname{Exp}(B)$ & $95 \% \mathrm{CI}$ & $\operatorname{Exp}(B)$ \\
\hline & & & & & & & lower & upper \\
\hline Chronological age & .01 & .010 & .01 & 1 & .92 & 1.01 & .83 & 1.23 \\
\hline Abilities profile & .05 & .04 & 1.52 & 1 & .22 & 1.05 & .97 & 1.13 \\
\hline Individualization & -.02 & .60 & .00 & 1 & .98 & .99 & .30 & 3.20 \\
\hline Adult-child interaction & .66 & 1.11 & .35 & 1 & .55 & 1.93 & .22 & 16.83 \\
\hline $\begin{array}{l}\text { Quality of } \\
\text { interaction }\end{array}$ & -3.36 & 1.34 & 6.29 & 1 & .01 & .04 & .00 & .48 \\
\hline Constant & 7.55 & 7.46 & 1.02 & 1 & .31 & 1896.00 & & \\
\hline
\end{tabular}

